\title{
Assessing Teacher's Knowledge, Self-efficacy, and Practices (KSP) in Adopting Flexible Learning during the Covid-19 Pandemic
}

\author{
Alberto D. Yazon ${ }^{1, *}$, Eden C. Callo ${ }^{2}$ \\ ${ }^{1}$ Curriculum and Instruction Development, and Quality Assurance, Laguna State Polytechnic University, Philippines \\ ${ }^{2}$ Academic Affairs, Laguna State Polytechnic University, Philippines
}

Received November 9, 2020; Revised December 18, 2020; Accepted January 20, 2021

\section{Cite This Paper in the following Citation Styles}

(a): [1] Alberto D. Yazon, Eden C. Callo, "Assessing Teacher's Knowledge, Self-efficacy, and Practices (KSP) in Adopting Flexible Learning during the Covid-19 Pandemic," Universal Journal of Educational Research, Vol. 9, No. 1, pp. 136 - 144, 2021. DOI: 10.13189/ujer.2021.090115.

(b): Alberto D. Yazon, Eden C. Callo (2021). Assessing Teacher's Knowledge, Self-efficacy, and Practices (KSP) in Adopting Flexible Learning during the Covid-19 Pandemic. Universal Journal of Educational Research, 9(1), 136 - 144. DOI: 10.13189/ujer.2021.090115.

Copyright $(2021$ by authors, all rights reserved. Authors agree that this article remains permanently open access under the terms of the Creative Commons Attribution License 4.0 International License

\begin{abstract}
As the whole world is facing the Pandemic COVID-19 crisis, where the conventional way of teaching-learning process, face-to-face interaction between students and teachers has suspended due to modified/general enhanced community quarantine, the action of the government to control and mitigate the spread of the disease, the educational landscapes of higher education institutions have been changed. This descriptive correlational research using the predictive method assessed teachers' knowledge, self-efficacy, practices, and perceived effectiveness in adopting flexible learning. The instruments used in this study were validated by experts in the fields of educational management, curriculum and instruction, quality assurance, research, and statistics. It obtained a reliability coefficient of Cronbach $\alpha=0.955$ which indicated an excellent reliability index. The responses from 531 faculties at the Laguna State Polytechnic University were generated through online survey. The results were analyzed using mean and standard deviation, multiple linear regression analysis. Structural Equation Modeling (SEM) was performed to determine the significant predictors of respondent's self-assessed effectiveness in adopting flexible learning. The study revealed that their knowledge and self-efficacy significantly explain $38.50 \%$ of the regular faculty's scores in their self-assessed effectiveness in adopting a flexible learning approach and practices in this alternative mode for
\end{abstract}

the new normal. Moreover, the SEM using confirmatory factor analysis disclosed that the observed parameters of teachers' knowledge, self-efficacy, and practices covary and significantly explain their self-assessed effectiveness in flexible learning. Hence, the Laguna State Polytechnic University's senior officials may customize flexible learning to suit the readiness of faculty, capacitate them as they shift to this alternative mode of instructional delivery, and capitalize the acquired technological and pedagogical content knowledge instead of the Learning Continuity Plan.

Keywords COVID-19, Teacher's Knowledge, Self-efficacy, Practices, Flexible Learning

\section{Introduction}

The COVID-19 pandemic has caused major shocks in all sectors of our society [1]. As the world becomes volatile, uncertain, complex, and ambiguous, so do the challenges we experience. This pandemic has brought unprecedented impact and has affected people regardless of socio-economic characteristics, especially the less advantaged members of the society [2]. The education system worldwide, including the Philippines, is now 
shifting from the traditional face-to-face instruction to online distance teaching-learning modalities. The new normal necessitates equity for all learners in terms of access to technology that support their learning. However, the digital divide is continuously increasing due to students' rare opportunity in the poverty line, including those in remote or far-flung areas.

The community quarantines in response to COVID-19 have impeded traditional schooling due to school closures. In just a few short months, this pandemic created a huge impact [3], creating significant confusion [4] and disturbance in education. It has reconfigured learning as digital, flexible, remote, and unstructured, limiting most learners to be engaged and connected. According to UNESCO, there are 1.6 billion learners across grade levels who have been out of school during this pandemic, which propels school leaders to maximize the resources to bridge this gap. Leadership and management practices, as well as teaching frameworks, have been significantly re-organized [5].

In the Philippines, due to more than 300000 COVID-19 cases since October 2020, primary education and higher education institution immediately shifted from physical to digital learning. Consequently, the Commission on Higher Education (CHED) encouraged Higher Education Institutions in the Philippines to survey the implementation of flexible learning as a strategy to cope with the challenges brought by the COVID-19 pandemic in the Philippine higher education system and to further come up with well-informed policies and directions in this regard.

Moreover, DepEd Order No. 12 s. 2020 and CHEd Memorandum Order No. 4 s. 2020 are cascaded to all schools, colleges, and universities to provide clear guidelines in the opening of classes this Academic Year $2020-2021$. These educational policies are anchored on the Inter-agency Task Force for the Management of Emerging Infectious Diseases (IATF) Resolutions Nos. $35 \mathrm{~A}-38$ to safeguard the spread of COVID-19 without compromising the continuity of learning [6].

CHEd reiterates the readiness and preparation of the HEI facilities to comply with minimum health standards such as the mandatory wearing of face masks and face shield, proper and regular sanitation practices, $1.50 \mathrm{~m}-2 \mathrm{~m}-$ physical distancing, reconfiguration of structured and unstructured learning spaces, provision of signposts in public places, the prohibition of social gathering, among others. Consultation with local health officials and local government units should be done to determine the health situation in the locality, availability of public transportation, and other support services necessary for the operation of HEIs. In consultation with stakeholders, preparation of a Contingency/Continuity plan as to the precautionary and other health protocols should be prepared in case there are suspected or confirmed cases.

As a response to the aforementioned national requirement, the Laguna State Polytechnic University had passed the LSPU Board Resolution No. 061 Series of 2020, approving the LSPU Learning Continuity Plan (LCP) with the following salient features: Curriculum and Instruction Framework for the New Normal and the Flexible Learning Delivery Model. The LSPU-LCP is deeply rooted in theoretical underpinnings which propel the conceptualization of this alternative flexible learning model that is more agile and receptive to the demand of time.

As educators and teachers are sailing with the "new normal," this is the appropriate time to look at the beauty in it and rewire their mindsets. The pandemic has highlighted the importance of teachers embracing technology to ensure the continuity and quality of learning [7]. Most teachers are continuously recording and uploading their instructional materials for the student's appreciation and consumption. Some were even more resourceful, creative, and innovative [8] and maximized the use of Learning Management System (LMS) such as Google Classroom, Moodle, Edmodo, and other equivalent learning platforms. Teachers are expected to try new pedagogical skills and competencies driven by technologies and modes of delivery [9], but it appears that many of them are struggling to thrive in this paradigm shift of content delivery [10].

One of the possible reasons for this challenge is that most teachers are not yet ready and prepared for flexible learning. When online teaching and learning is designed, it is crucial to cover participant familiarity and capability in using technology and their preparation to participate in this alternative delivery mode. Action plan or guidelines about how teaching and learning work in online environments may be in place [11].

As Toquerro (2020) narrows it down, there is a need to review and align the curriculum and extensively capacitate teachers to adjust to the new normal [9]. They need to upgrade to adapt to changes in their expanded roles and responsibilities. They deserve to acquire new skills to play a different role in preparing them to become multi-functional and versatile. Along with this premise, teachers are expected to be open and must rely on their firm belief that they have the capacity and capability for a particular task that has yet to be undertaken as they teach in the new normal.

Hence, this study recognizes and explores the teacher's knowledge, self-efficacy, and practices in adopting flexible learning. It aims to contribute to the existing preparation and training programs relevant to aspiring and practicing teachers. As most of the State Universities and Colleges in the Philippines, including LSPU, immediately shifted from the old normal to the new normal of the educational setting, action plan and faculty-training are deemed to be necessary and relevant. Capacitating the teaching force in the curriculum implementation will help LSPU achieve its ultimate goal of providing quality and equitable education amidst the challenging time. 


\section{Problem Statement and Research Questions}

Recognizing teachers' knowledge, self-efficacy, and practices in adopting flexible learning play an essential role as higher education institutions' educational landscapes have been changed. The literature suggests that teacher knowledge, self-efficacy, and practices are constructs that can be investigated if the respondent's self-assessed effectiveness in using flexible learning is to be examined.

Hence, this study explored the following research questions:

1. What is the level of teacher knowledge in flexible learning?

2. What is the level of the respondent's capability of doing critical flexible learning activities?

3. What is the level of the respondent's use of technology devices in doing flexible learning tasks?

4. What is the respondent's perception of the degree of effectiveness to practice the equitable, flexible learning strategies?

5. Do the respondent's knowledge, self-efficacy, and practices predict their effectiveness in practicing equitable, flexible learning strategies?

\section{Research Methods}

\subsection{Research Design}

The present study is quantitative research with descriptive-correlational, particularly explanatory (predictive) as the primary method in analyzing the data. It is quantitative as the researcher is detached from participants and strives to be objective and summarizes the results numerically (Lodico, Spaulding, and Voegtle, 2006). It is a prediction since it examined correlations between variables and identified one or more variables (knowledge, self-efficacy, and practices) that can predict changes in another variable measured (self-assessed effectiveness).

\subsection{Context and Participants}

The present study was conducted at the Laguna State Polytechnic University (LSPU), Philippines. The questionnaire was sent via private message, and e-mailed to the university's regular and part-time faculty. A sample of 531 out of $881(60.27 \%)$ usable responses were obtained from four (4) LSPU Campuses. The respondents were asked to describe their characteristics.

They were also asked to respond about the 4-point and 5-point Likert-type scales on the constructs discussed in the instrument sub-section below. The Santa Cruz-Main Campus registered with the highest number of respondents, with 195 (36.70\%). It is followed by Siniloan Campus (135; 25.4\%), San Pablo City Campus (134, 25.2\%), and Los
Banos $(67 ; 12.6 \%)$. There were more female respondents $(316 ; 59.5 \%)$ than male respondents $(215 ; 40.5 \%)$. The majority of the faculty - respondents who participated were below 40 years old $(291 ; 54.8 \%)$. It indicates that digital natives outnumbered this group. More than half of the teachers $(300 ; 56.5 \%)$ are regular faculty and master's degree to doctorate holders. There were $360(67.8 \%)$ teachers in the teaching profession for about ten (10) years on the date this study was conducted.

\subsection{Research Instrument}

The authors developed the Teacher Knowledge, Self-efficacy, and Practices (KSP) in flexible learning instruments with reference to the related literature and studies emphasizing the theories and models that underpin the latent constructs of this study. This online survey instrument included the following components:

1. Personal Characteristics. It asks the respondent's campus location, sex, age, employment status, highest educational attainment, and service length.

2. Knowledge. It is a 10-item questionnaire that solicits respondents' understanding of the characteristics and nature of flexible learning. It is a 4 - point Likert-type scale, with options ranging from 1 (Not Knowledgeable) to 4 (Very Knowledgeable). Based on the CFA, the ten items of the knowledge construct have an excellent factor loading, all greater than 0.40 (see Figure 1). The values indicate that the ten indicative statements well-represent the measured variable (knowledge of flexible learning).

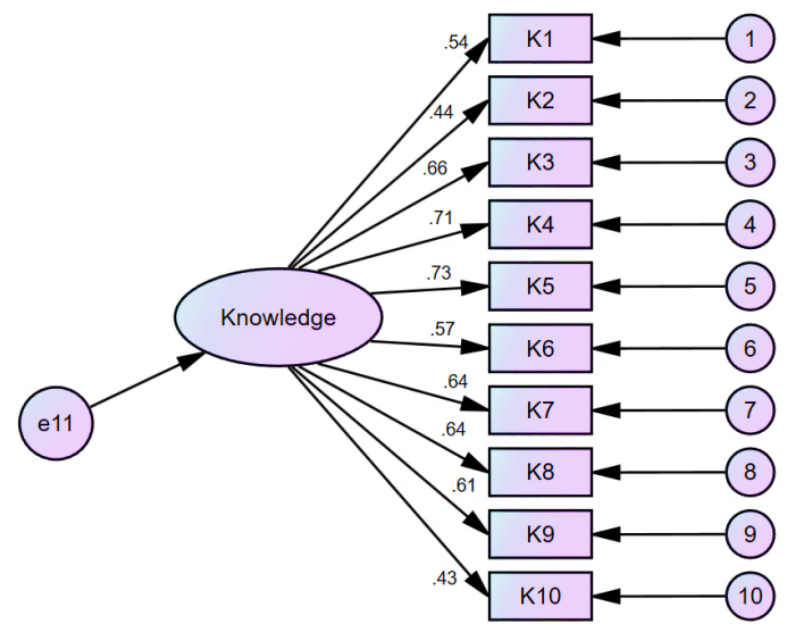

Figure 1. Confirmatory Factor Analysis (CFA) Model of Teacher Knowledge in Flexible Learning

3. Self - efficacy. Self-efficacy is the teacher's self-assessed abilities that they can perform a particular teaching task with confidence. This study is a 10 - item assessment tool that asks the respondent's assessment of their ability to do flexible learning strategies. They rated themselves using a scale of one (1, I cannot do it) to five (5, I can do it very well.). Based on the CFA, the ten items of the self-efficacy 
construct have an excellent factor loading, which is greater than 0.70 (see Figure 2). The values indicate that the 10 benchmark statements well-represent the measured variable (self-efficacy on flexible learning).

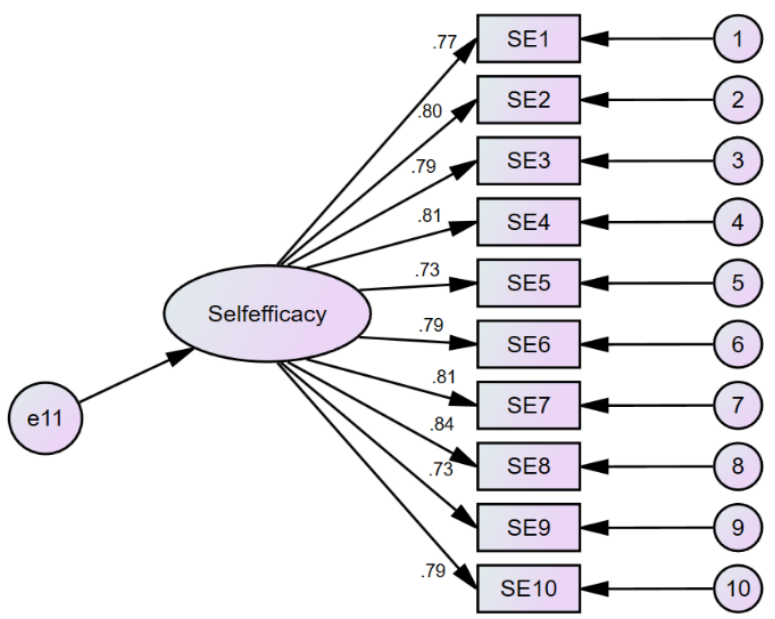

Figure 2. Confirmatory Factor Analysis (CFA) Model of Teacher Self-efficacy in Flexible Learning

4. Practices. This 8 - item questionnaire gauges the frequency of respondents' use of technology in online teaching and learning. It is a 4 - point Likert-type scale, with anchors ranging from 1 (Never) to 4 (Everyday). Based on CFA results, the ten items of the construct practices have an OK factor loading, which is all greater than 0.50 (see Figure 3). The values specify that the eight (8) indicators well-represent the measured variable (practices on flexible learning).

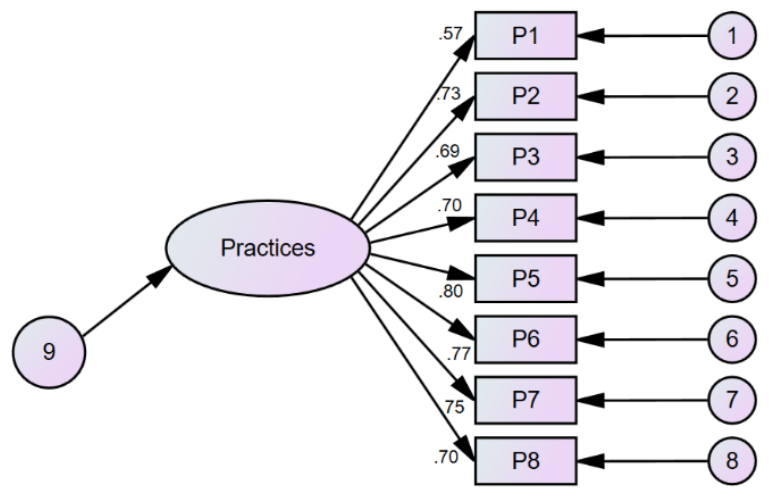

Figure 3. Confirmatory Factor Analysis (CFA) Model of Teacher Practices in Flexible Learning

5. Effectiveness. This 5-item self-assessment tool measures the teacher respondents' perception of the degree of effectiveness to practice flexible learning strategies. They rated themselves using one (1, Not effective) scale to five (5, Very much convincing). The CFA Model shows that the five (5) parameters on teachers' self-assessed effectiveness in flexible learning well-measure the said construct as evidenced by the excellent factor loading, which are all greater than 0.60 (see Figure 4).

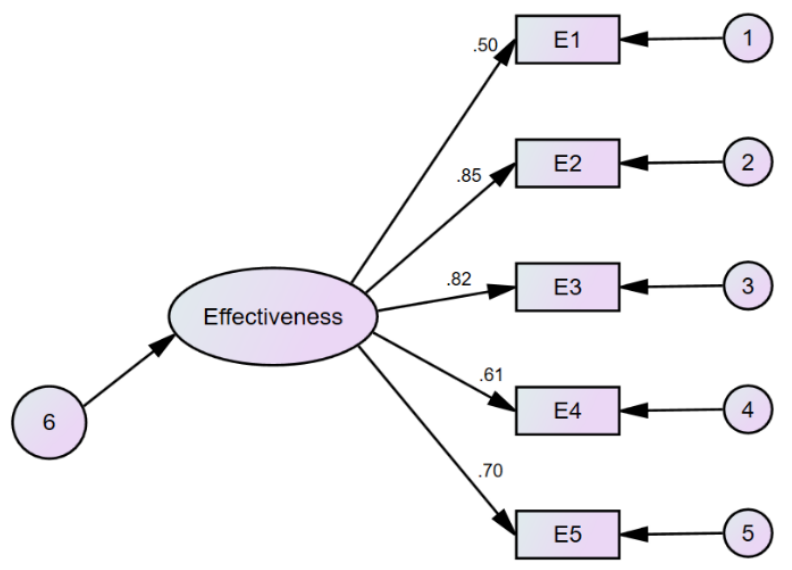

Figure 4. Confirmatory Factor Analysis (CFA) Model of Teacher Self-assessed Effectiveness in Flexible Learning

The researchers-made online survey instrument was content - validated by experts in educational management, quality assurance, statistics, and research. It is highly accepted in terms of suitability and appropriateness of items and reported an excellent reliability index of Cronbach $\alpha=0.955$. It was programmed in google form, and the extracted data were analyzed using descriptive statistics such as percent, weighted mean, and standard deviation. Multiple linear regression analysis using the Enter Method was employed to determine the significant predictors of respondent's self-assessed effectiveness in adopting flexible learning. Moreover, the Structural Equation Modeling (SEM) using confirmatory factor analysis (CFA) was used to determine if the observed parameters of teachers' knowledge, self-efficacy, and practices covary and significantly explain their self-assessed effectiveness in flexible learning.

\section{Results}

\subsection{On Knowledge in Flexible Learning}

Based on the results in Table 1, the respondents are knowledgeable that they are not the only source of knowledge and information $(\bar{x}=3.42)$. They recognize that the learning outcomes are the competencies that the students must demonstrate after a course of study $(\bar{x}=3.36)$ and that flexible learning increases the diversity of learning contexts and experiences $(\bar{x}=3.22)$. The respondents are aware that constructive alignment is the congruence of teaching and learning activities to the learning outcomes $(\bar{x}$ $=3.21)$ and requires a learner-centered approach $(\bar{x}=3.11)$. 
Table 1. Respondent's Knowledge of Flexible Learning

\begin{tabular}{llll}
\hline & \multicolumn{1}{c}{ Indicative Statement } & $\overline{\boldsymbol{x}}$ & Description \\
\hline 1. & Students can learn at their own pace. & 2.76 & Knowledgeable \\
2. & Teachers are not the only sole source of knowledge and information. & 3.42 & Knowledgeable \\
3. & Flexible learning increases the diversity of learning contexts and experiences. & 3.22 & Knowledgeable \\
4. & Flexible learning allows students to demonstrate course-specific learning objectives. & 2.96 & Knowledgeable \\
5. & $\begin{array}{l}\text { Pedagogical flexibility refers to the implementation, interaction, assessment, and media of } \\
\text { instruction. }\end{array}$ & 3.08 & Knowledgeable \\
6. & $\begin{array}{l}\text { Location, time, and pace of learning denote logistical flexibility. } \\
\text { 7. }\end{array} \quad \begin{array}{l}\text { Learning outcomes are the competencies that the students must be able to demonstrate after a course } \\
\text { of study. }\end{array}$ & 3.03 & Knowledgeable \\
8. & $\begin{array}{l}\text { Constructive alignment is the congruence of teaching and learning activities to the learning } \\
\text { outcomes. }\end{array}$ & 3.21 & Knowledgeable \\
9. & $\begin{array}{l}\text { Flexible learning is a learner-centered approach. } \\
\text { 10. }\end{array}$ Flexible learning is not always an online approach. & 3.11 & Knowledgeable \\
\hline & $\quad$ Composite & 2.83 & Knowledgeable \\
\hline
\end{tabular}

Legend: $\quad 3.50-4.00=$ Highly Knowledgeable; $2.50-3.49=$ Knowledgeable;

$\mathrm{N}=531$

$1.50-2.49=$ Quite Knowledgeable; $1.00-1.49=$ Not Knowledgeable

The faculty are knowledgeable that pedagogical flexibility refers to the implementation, interaction, assessment, and media of instruction $(\bar{x}=3.08)$, and logistical flexibility pertains to a location, time, and pace of learning $(\bar{x}=3.06)$. Although the mean scores on the following benchmark statements are interpreted as "knowledgeable," they were evaluated as the least indicators from which the respondents may take into consideration: flexible learning allows students to demonstrate course-specific learning objectives; flexible learning is not always an online approach; students can learn at their own pace.

\subsection{On Self-efficacy in Flexible Learning}

Table 2. Respondents' Self-Efficacy in Flexible Learning

\begin{tabular}{|c|c|c|c|}
\hline & Indicative Statement & $\bar{x}$ & Description \\
\hline 1. & $\begin{array}{l}\text { Out of class homework linked to } \\
\text { in-class activities }\end{array}$ & 3.71 & I can do it well \\
\hline 2. & $\begin{array}{l}\text { Library copyright-cleared } \\
\text { online readings }\end{array}$ & 3.92 & I can do it well \\
\hline 3. & $\begin{array}{l}\text { Learning guides/modules and } \\
\text { course notes }\end{array}$ & 3.89 & I can do it well \\
\hline 4. & Online quizzes & 3.56 & I can do it well \\
\hline 5. & $\begin{array}{l}\text { Off-line learning application/ } \\
\text { software }\end{array}$ & 3.37 & $\begin{array}{l}\text { I can do it } \\
\text { satisfactorily }\end{array}$ \\
\hline 6. & Digital media presentations & 3.77 & I can do it well \\
\hline 7. & Communication by group blogs & 3.56 & I can do it well \\
\hline 8. & $\begin{array}{l}\text { Data collection, organization, } \\
\text { and representation }\end{array}$ & 3.61 & I can do it well \\
\hline 9. & $\begin{array}{l}\text { Digital media-based } \\
\text { assignments }\end{array}$ & 3.72 & I can do it well \\
\hline 10. & $\begin{array}{l}\text { Series of individual and group } \\
\text { performance tasks/assignments }\end{array}$ & 3.67 & I can do it well \\
\hline & Composite & 3.68 & I can do it well \\
\hline
\end{tabular}

Legend: $\quad 4.50-5.00-\mathrm{I}$ can do it very well; $\quad 3.50-4.49-\mathrm{I}$ can do it well $\quad \mathrm{N}=531$

$2.50-3.49-$ I can do it satisfactorily; $1.50-2.49-\mathrm{I}$ can do it to a small extent. $\quad 1.00-1.49-$ I cannot do it
The results presented in Table 2 indicates that the respondents can do it well when assigning library copyright-cleared online readings to students $(\bar{x}=3.92)$ and in preparing learning guides/modules and course notes $(\bar{x}=3.89)$ and digital media presentations $(\bar{x}=3.77)$. With a mean score of 3.72 and 3.71 , the respondents can assign well digital media-based assignments to students and out of class homework linked to in-class activities, respectively. They can confidently assign a series of individual and group performance tasks/assignments $(\bar{x}=3.67)$ and process student's output on data collection, organization, and representation $(\bar{x}=3.61)$. Admittedly, they can least prepare and administer online quizzes, communicate by group blogs, and need more exposure and familiarity on the use of off-line learning applications/ software.

\subsection{On Practices in Flexible Learning}

Table 3. Respondents' Practices in Flexible Learning

\begin{tabular}{|c|c|c|c|}
\hline & Indicative Statement & $\overline{\boldsymbol{x}}$ & Description \\
\hline 1. & Online research & 2.66 & 2-4 Times a Week \\
\hline 2. & $\begin{array}{l}\text { Complete an assessment } \\
\text { task }\end{array}$ & 2.72 & 2-4 Times a Week \\
\hline 3. & Watch a video & 2.71 & 2-4 Times a Week \\
\hline 4. & Listen to audio & 2.58 & 2-4 Times a Week \\
\hline 5. & Complete homework & 2.79 & 2-4 Times a Week \\
\hline 6. & Practice skills & 2.91 & 2-4 Times a Week \\
\hline 7. & Express ideas creatively & 3.04 & 2-4 Times a Week \\
\hline 8. & $\begin{array}{l}\text { Prepare } \\
\text { presentations/reports }\end{array}$ & 2.83 & 2-4 Times a Week \\
\hline & Composite & 2.78 & 2-4 Times a Week \\
\hline
\end{tabular}

Legend: $3.50-4.00$ - Everyday; $2.50-3.49-2-4$ Times a week

$\mathrm{N}=531 . \quad 1.50-2.49-$ Once $a$ week 1.00-1.49-Never

As shown in Table 3, the respondents reported that they frequently express ideas creatively $(\overline{x=3.04})$ and let students practice skills $(\bar{x}=2.91)$. More often, the teachers prepare presentations/reports $(\bar{x}=2.83)$ and assign students homework to complete $(\bar{x}=2.79)$. Oftentimes, they allow 
students to complete an assessment task and watch a video with a mean score of 2.72 and 2.71 , respectively. Letting students do an online search and listen to audio is less practiced by the flexible learning respondents.

\subsection{On Self-assessed Effectiveness in Flexible Learning}

Table 4. Respondents' Self-assessed Effectiveness in Flexible Learning

\begin{tabular}{|c|c|c|c|}
\hline & Indicative Statement & $\overline{\boldsymbol{x}}$ & Description \\
\hline 1. & Teaching live & 3.66 & Much Effective \\
\hline 2. & $\begin{array}{l}\text { Recording short instructional } \\
\text { videos }\end{array}$ & 3.56 & Much Effective \\
\hline 3. & $\begin{array}{l}\text { Taking the correspondence } \\
\text { model }\end{array}$ & 3.39 & $\begin{array}{l}\text { Moderately } \\
\text { Effective }\end{array}$ \\
\hline 4. & $\begin{array}{l}\text { Putting lectures into text/ } \\
\text { converting into pdf copy and } \\
\text { send to students at home }\end{array}$ & 3.63 & Much Effective \\
\hline 5. & $\begin{array}{l}\text { Being creative and thinking } \\
\text { out of the box }\end{array}$ & 3.93 & Much Effective \\
\hline & Composite & 3.63 & Much Effective \\
\hline
\end{tabular}

Legend: 4.50 - 5.00 - Very Much Effective; 3.50 - 4.49 - Much Effective $\quad \mathrm{N}=531$

2.50 - 3.49 - Moderately Effective; 1.50 - 2.49 - Less Effective 1.00 - 1.49 - Not Effective

When the respondents were asked about their perception of the degree of effectiveness to practice the flexible learning strategies, they stated that they are very effective $\mathrm{i}$ at being creative and thinking out of the box $(\bar{x}=3.93)$. They believe that they are much useful in teaching life $(\bar{x}=$ 3.66) and putting lectures into text/ converting into pdf copy and send to students at home $(\bar{x}=3.63)$. However, they are quite hesitant in stating that they effectively record short instructional videos $(\bar{x}=3.56)$ and moderately effective in taking the correspondence model $(\bar{x}=3.39)$.

\subsection{On the Test of Significant Prediction}

Multiple linear regression using Enter Method was performed to predict the respondents' effectiveness in adopting flexible learning based on their knowledge, self-efficacy, and practices. A significant regression equation was found $F(3,527)=111.371, p<.001)$, with an $R^{2}=$ of .388 .
Participant's predicted effectiveness (E) is equal to

$$
\mathrm{E}=0.977+0.374 \mathrm{~S}+0.254 \mathrm{~K}+0.179 \mathrm{P}
$$

where $\mathbf{0 . 9 7 7}$ is constant, $\mathbf{S}=$ self-efficacy score, $\mathbf{K}=$ knowledge score, and $\mathbf{P}=$ practices score.

The equation tells that for every one (1) point increase in the respondent's perceived effectiveness in adopting flexible learning, the model predicts 0.374 points increase in their self-efficacy, holding the knowledge and practices constant. Moreover, for every one (1) point increase in the respondent's perceived effectiveness in adopting flexible, the model predicts 0.254 points increase in their knowledge scores, holding the self-efficacy and practices scores fixed. The model also predicts that for every one (1) point increase in the respondent's perceived effectiveness in adopting flexible learning, their practice scores will increase by 0.179 , keeping the other two predictor variables constant.

The model further revealed that $38.5 \%$ of the variation on participants' self-assessed effectiveness score is significantly explained by knowledge, self-efficacy, and practices in adopting flexible learning, with self-efficacy as the former's best predictor.

Table 5. Test of Significant Prediction of Knowledge, Self-efficacy, and Practices on Self-assessed Effectiveness in Adopting Flexible Learning

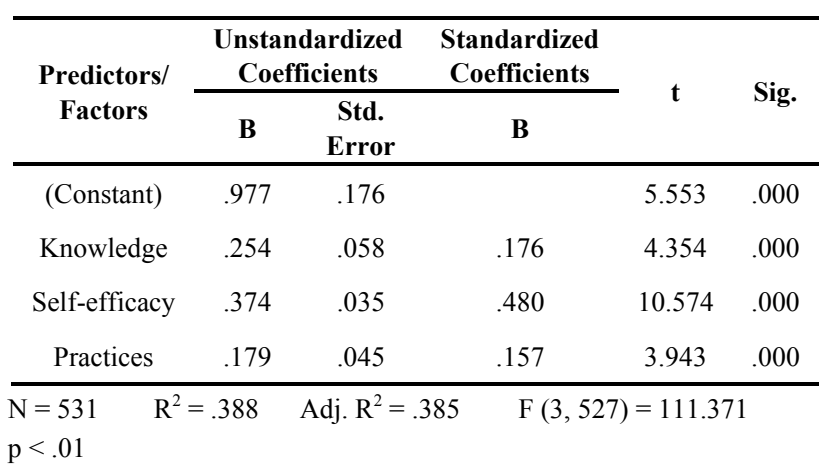

Structural Equation Model (SEM) using Confirmatory Factor Analysis was performed to provide a theoretical model of the significant influence of teacher's Knowledge, Self-Efficacy, and Practices to their self-assessed effectiveness in adopting flexible learning in the new normal (see Figure 5). 


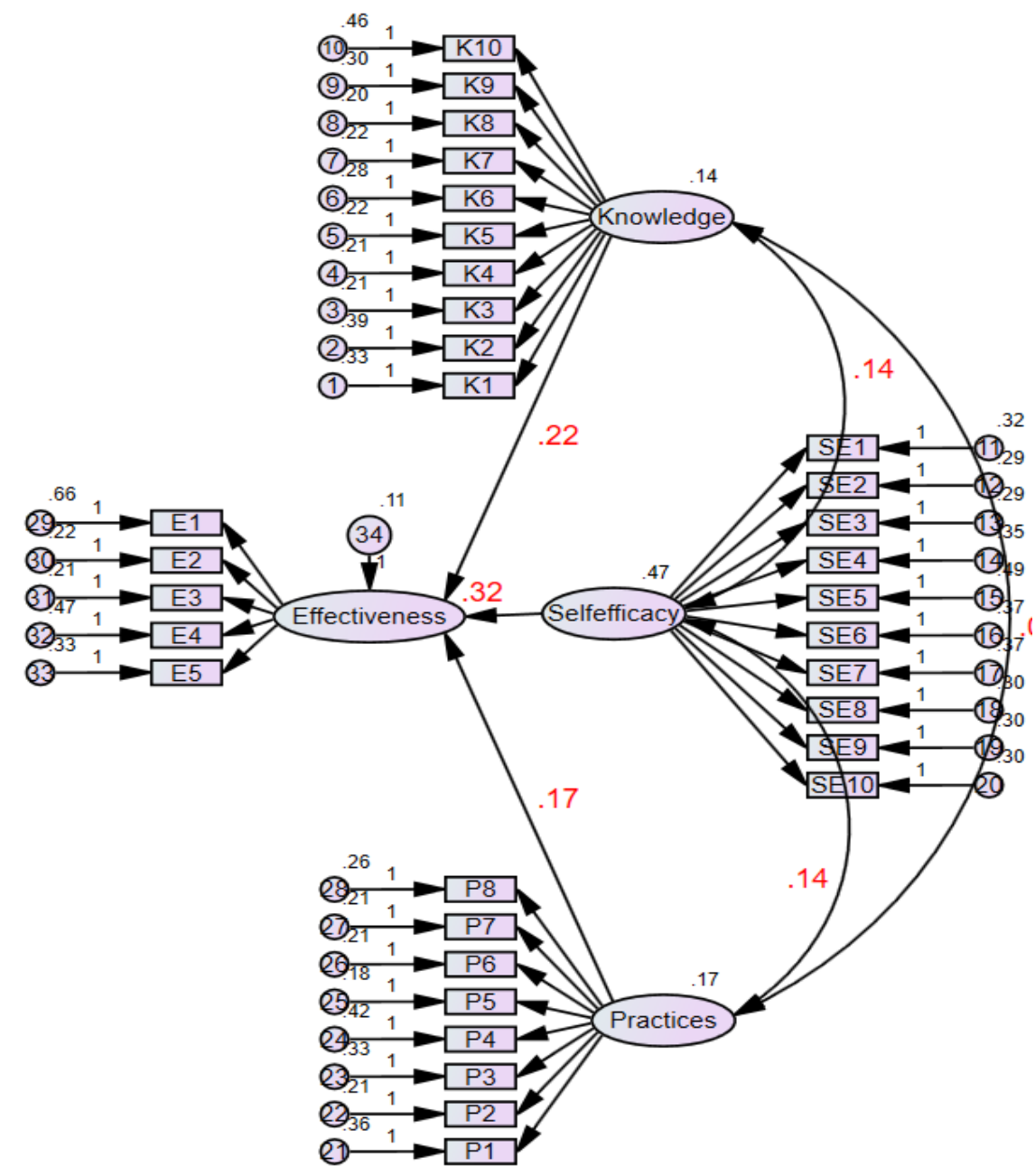

Figure 5. Knowledge, Self-efficacy, and Practices (KSP) Structural Equation Model

The model presented in Figure 5 is called the structural equation model of teacher's Knowledge, Self-Efficacy, and Practices (KSP) in Flexible Learning. The Structural Equation Model has several variables -33 observed and 38 unobserved variables; 37 exogenous (independent) and 34 endogenous (dependent) variables. This study used maximum likelihood estimation (MLE), an alternative ordinary least square (OLS) in the multiple regression models already presented. Being superior to OLS, MLE had iteratively improved parameter estimates to minimize the specified fit functions, which were pre-set on AMOS before estimation analysis was run. AMOS has counted 561 distinct sample moments, and with 72 distinct parameters estimated, the degree of freedom was 489.

It can be observed that there is an abundance of fit indices, and it becomes an attraction to choose to select the measure that would substantiate the best fit. The Comparative Fit Index (CFI), Goodness of Fit Index (GFI), Normed Fit Index (NFI), and the Non-normed Fit Index (NNFI) are the most commonly reported fit indices [12]. Different indices reflect a different model fit, including the Model Chi-Square and its degrees of freedom and associated p-value.
Table 6. Measures of Fit Summary of KSP Model

\begin{tabular}{|c|c|c|c|}
\hline Measures of Fit & Criteria & Values & Interpretation \\
\hline \multicolumn{4}{|l|}{ Global Fit } \\
\hline Chi - square $\left(x^{2}\right)$ GOF & $p>0.05$ & 0.002 & Acceptable Fit \\
\hline $\begin{array}{l}\text { Relative or Normed Chi } \\
\text { - square Value }\end{array}$ & $2<x^{2}<5$ & 3.254 & Good Fit \\
\hline \multicolumn{4}{|l|}{ Absolute Fit Indices } \\
\hline $\begin{array}{l}\text { Goodness - of - Fit } \\
\text { Index (GFI) }\end{array}$ & $\geq 0.90$ & 0.838 & Acceptable Fit \\
\hline $\begin{array}{l}\text { Root Mean Square Error } \\
\text { of Approximation } \\
\text { (RMSEA) }\end{array}$ & $<0.05$ & 0.066 & Acceptable Fit \\
\hline $\begin{array}{l}\text { Root Mean Square } \\
\text { Residual (RMR) }\end{array}$ & $<0.10$ & 0.031 & Good Fit \\
\hline \multicolumn{4}{|l|}{ Incremental Fit Indices } \\
\hline Normed Fit Index (NFI) & $\geq 0.90$ & 0.839 & Acceptable Fit \\
\hline $\begin{array}{c}\text { Tucker - Lewis Index } \\
\text { (TLI) }\end{array}$ & $\begin{array}{c}\text { Close to } \\
1\end{array}$ & 0.873 & Acceptable Fit \\
\hline $\begin{array}{l}\text { Comparative Fit Index } \\
\text { (CFI) }\end{array}$ & $>0.90$ & 0.882 & Acceptable Fit \\
\hline \multicolumn{4}{|l|}{ Parsimony Fit Indices } \\
\hline $\begin{array}{l}\text { Adjusted Goodness - of } \\
\text { - Fit Index (AGFI) }\end{array}$ & $\begin{array}{c}\text { Close to } \\
1\end{array}$ & 0.814 & Acceptable Fit \\
\hline $\begin{array}{l}\text { Parsimony Normed Fit } \\
\text { Index (PNFI) }\end{array}$ & $\begin{array}{c}\text { Close to } \\
1\end{array}$ & 0.777 & Acceptable Fit \\
\hline
\end{tabular}


Moreover, Standardized Root Mean Square Residual (SRMR) with the NNFI (Tucker - Lewis Index), Root Mean Square Estimates of Approximation (RMSEA), or the CFI may also be looked into. Stemming from these perspectives, the fit summary of the KSP Model in Table 6 shows that the structural equation model has acceptable to good fit indices.

\section{Discussion}

Due to the COVID-19 pandemic, the teaching and learning process has shifted to more agile and resilient learning options designed to make education accessible to all. It propels the teachers to learn new things to develop learner-driven experiences, emphasizing engaging students, and giving a sense of agency. Educators and teachers have unlearned old rules, knowledge, or beliefs or what was learned or done before migrating to the new normal [18].

The pandemic has significant impact on the education sector as it shifted the learning environment from physical to digital. It has transformed the congested standards into the essential learning competencies that empower student habits. It offers a more significant learning opportunity to teachers in reconfiguring their challenges into more innovative pedagogical practices [13]. Flexible learning is emergent, allowing teachers to develop collaborative learning tasks in mixed-ability groupings [14, 17]. Teaching and learning in the new normal dramatically increase the flexible and remote alternative modalities and are considered one of the most strategic priorities in today's educational system.

Providing accessible online and printed tools supports and enables learners to have an equal chance to educational opportunities [15]. This teaching and learning practice may lessen achievement gaps and mitigate barriers that learners face based on their sociodemographic characteristics [16]. To create active citizens and lifelong learners, the teachers should always know and understand what to teach and how to help students learn.

This study highlights the importance of knowledge, self-efficacy, and practices attuned to the current situation. Customization, capacitation, and capitalization of teachers' inherent potentials would significantly impact students' learning, even if they are situated in a flexible learning environment. Since this study proves that teachers' knowledge, self-efficacy, and practices significantly explain their self-assessed effectiveness in adopting flexible learning, teachers may be inspired to innovate by investing on these attributes to provide efficient, effective, and quality instruction to students amidst these challenging times.

\section{Conclusions}

The COVID-19 pandemic heightens the shifts in society, economy, and the role of technology, consequently influencing the direction our education system is navigating. From an outdated traditional schoolhouse model of education to the new normal culture of education model, this paradigm shift in the educational landscape propels stakeholders' evolving roles, especially the teachers and educators.

Teachers' knowledge and self-efficacy on the use of social media, mobile phones, and other digital tools, including well-designed printed learning modules, offer various opportunities to make learning accessible to all learners. Being adaptive to the current situation and the resourcefulness to adopt the new ways of teaching and assessing students' learning are desirable teachers' desirable traits in this challenging time.

This digital transformation also sparks teachers' innovation and desire to continue learning while fine-tuning their practices to become better teachers every day. Although today's primary focus is the essential learning competencies, it still necessitates the most effective teaching and learning strategy to help students learn.

\section{Recommendations}

In the desire to provide equitable, accessible, and quality instruction, the following may be considered:

1. The pedagogical content knowledge of teachers may be reconfigured through faculty training programs or activities.

2. The school leaders may extend support to teachers and ensure that the same vision and purpose guide them.

3. The validity and reliability of assessment practices may be established to ensure that the students' desired learning competencies are efficiently acquired.

4. A training manual for teachers that may serve as their guide in implementing flexible learning may be designed.

5. A sound university policy that may further support a teacher's social presence, cognitive presence and teaching presence in the new teaching and learning modalities may be planned and proposed.

\section{REFERENCES}

[1] Organization for Economic Co-operation and Development (OECD). https://www.oecd.org/coronavirus/en/\#highlights

[2] Schleicher, A. (2020). The Impact of Covid-19 on Education, Insights from Education at a Glance 2020. O 26(6), 729-734

[3] Azorín, C. (2020). "Beyond COVID-19 Supernova. Is Another Education Coming?" Journal of Professional 
Capital and Community. https://www.emerald.com/insight/ publication/issn/2056-9548

[4] Hargreaves, A., and M. Fullan (2020). "Professional Capital after the Pandemic: Revisiting and revising Classic Understandings of Teachers' Work." Journal of Professional Capital and Community. https://www.emerald.com/insight/ publication/issn/2056-9548

[5] Zhao, Y. (2020). "COVID-19 as a Catalyst for Educational Change." Prospects, 1-5. doi:10.1007/s11125-020-09477-y.

[6] Guidelines for the Prevention, Control and Mitigation of the Spread of Coronavirus Disease 2019 (COVID-19) in Higher Education Institutions (HEIs) CHED COVID ADVISORY No. 724 May 2020

[7] Gamiao, A. (2020). Importance of innovative teaching in the new normal. Manila Times. https://www.manilatimes.net/2 020/07/30/campus-press/importance-of-innovative-teaching -in-the-new-normal/747677/

[8] Fox, R. (2007). SARS epidemic: Teachers' experiences using ICTs. Retrieved from https://www.google.com/url?sa $=\mathrm{t} \&$ source $=$ web\&rct $=\mathrm{j} \&$ url $=\mathrm{https}: / / \mathrm{www}$.ascilite.org $/$ confer ences/perth04/procs/pdf/fox.pdf\&ved=2ahUKEwi83IjD2N 3oAhWm-GEKHRgcCCUQ FjABegQIAhAB\&usg=AOvVaw1pZFXsa8vwVtg_19X7Y wtN

[9] Eickelmann, B., and J.Gerick . 2020. "Lernen Mit Digitalen Medien: Zielsetzungen in Zeiten Von Corona Und Unter Besonderer Berücksichtigung Von Sozialen Ungleichheiten [Learning with Digital Media: Objectives in Times of Corona and under Special Consideration of Social Inequities]." Die Deutsche Schule 16: 153-162.

[10] Toquero, C. (2020). Challenges and Opportunities for Higher Education amid the COVID-19 Pandemic: The Philippine Context. Pedagogical Research, 5(4), em0063. https://doi.org/10.29333/pr/7947

[11] Eden C. Callo, Alberto D. Yazon (2020). Exploring the
Factors Influencing the Readiness of Faculty and Students on Online Teaching and Learning as an Alternative Delivery Model for the New Normal. Universal Journal of Educational Research, 8(8), 3509 - 3518. DOI: 10.13189/ujer.2020.080826.

[12] McDonald, R.P., and Ho, M.-H.R. (2002). "Principles and Practice in Reporting Statistical Equation Analyses, "Psychological Methods, 7 (1), 64-82.

[13] Gordon, N. A. (2014). Flexible Pedagogies: technology-enhanced learning. In The Higher Education Academy. https://doi.org/10.13140/2.1.2052.5760

[14] Barr, B., \& Miller, S. (2013). Higher Education: The Online Teaching and Learning Experience. Retrieved from https://www.google.com/url?sa=t\&source=web\&rct=j\&url $=$ https://files.eric.ed.gov/fulltext/ED543912.pdf\&ved=2ahU KEwiS3t

KI2N3oAhUm-2EKHfNoCR8QFjABegQIAxAB\&usg=AO vVaw10Sal8UOXPU8DFS3h782jT

[15] Ludeman, R., Osfield, K., Hidalgo, E. I., Oste, D., \& Wang, H. (2009). Student Affairs and Services in Higher Education: Global Foundations, Issues, and Best Practices. United Nations Educational, Scientific and Cultural Organization, France. Retrieved from https://unesdoc.unesco.org/ark:/482 23/pf0000183221

[16] Naidu, S. (2017). How flexible is flexible learning, who is to decide, and what are its implications?, Distance Education, 38:3, 269-272, DOI: 10.1080/01587919.2017.1371831

[17] Deed, C., Blake, D., Henriksen, J. et al. Teacher adaptation to flexible learning environments. Learning Environ Res 23, 153-165 (2020). https://doi.org/10.1007/s10984-019-09302 $-0$

Saxena, A. (2020). The Changing Role of the Educator in the New Normal. https://www.highereducationdigest.com/the-c hanging-role-of-the-educator-in-the-new-normal 